Louisiana State University

LSU Digital Commons

Faculty Publications

Department of Chemistry

6-15-2012

\title{
Thermal frontal polymerization with a thermally released redox catalyst
}

Claudio Attardo Parrinello

Louisiana State University

Christopher O. Bounds

Louisiana State University

Maria Liria Turco Liveri

Università degli Studi di Palermo

John A. Pojman

Louisiana State University

Follow this and additional works at: https://digitalcommons.Isu.edu/chemistry_pubs

\section{Recommended Citation}

Parrinello, C., Bounds, C., Liveri, M., \& Pojman, J. (2012). Thermal frontal polymerization with a thermally released redox catalyst. Journal of Polymer Science, Part A: Polymer Chemistry, 50 (12), 2337-2343.

https://doi.org/10.1002/pola.26013

This Article is brought to you for free and open access by the Department of Chemistry at LSU Digital Commons. It has been accepted for inclusion in Faculty Publications by an authorized administrator of LSU Digital Commons.

For more information, please contact ir@lsu.edu. 


\title{
Thermal Frontal Polymerization with a Thermally Released Redox Catalyst
}

\author{
Claudio Attardo Parrinello, ${ }^{1,2}$ Christopher O. Bounds, ${ }^{1}$ Maria Liria Turco Liveri, ${ }^{2}$ \\ John A. Pojman ${ }^{1}$ \\ ${ }^{1}$ Department of Chemistry, Louisiana State University, Baton Rouge, Louisiana 70803 \\ ${ }^{2}$ Parco D'Orleans II, Dipartimento Di Chimica Fisica, Viale Delle Scienze, Universita di Palermo, Palermo 90128, Italy \\ Correspondence to: J. A. Pojman (E-mail: john@pojman.com)
}

Received 6 December 2011; accepted 18 February 2012; published online 11 March 2012

DOI: $10.1002 /$ pola.26013

ABSTRACT: We studied thermal frontal polymerization using a redox system in an attempt to lower the temperature of the frontally polymerizable system while increasing the front velocity so as to obtain a self-sustaining front in a thinner layer than without the redox components. A cobalt-containing polymer with a melting point of $63{ }^{\circ} \mathrm{C}$ (Intelimer $6050 \times 11$ ) and cumene hydroperoxide were used with a triacrylate. The use of the Intelimer decreased the front velocity but allowed fronts to propagate in thinner layers and with more filler while still having a pot life of days. Nonplanar modes of propagation occurred. Fronts propagated faster when 6-O-palmitoyl-L-ascorbic acid was used as a reductant. Interestingly, fronts were also faster with the reductant even without the Intelimer if kaolin clay was the filler; however, the pot life was significantly reduced. (c) 2012 Wiley Periodicals, Inc. J Polym Sci Part A: Polym Chem 50: 2337-2343, 2012

KEYWORDS: acrylate; addition polymerization; frontal polymerization; kinetics; radical polymerization; redox polymers
INTRODUCTION Thermal frontal polymerization occurs when a monomer is converted to a polymer in a localized reaction zone that propagates through the coupling of thermal transport and the Arrhenius dependence of the reaction rate of an exothermic polymerization. ${ }^{1}$ We will refer to "thermal frontal polymerization" simply as "frontal polymerization."

Frontal polymerization was first discovered by Chechilo et al. $^{2}$ Frontal polymerization has many possible applications, including preparation of interpenetrating polymer networks, ${ }^{3}$ curing large composites, ${ }^{4-6}$ and material synthesis. ${ }^{7-10} \mathrm{Hu}$ et al. $^{11}$ used free-radical frontal polymerization to synthesize urethane-acrylate copolymers. Szalay et al. ${ }^{12}$ polymerized an alternating styrene-maleic anhydride copolymer using freeradical frontal polymerization. Chen et al. ${ }^{13}$ synthesized polyurethane-nanosilica hybrid nanocomposites. Pojman and McCardle $^{14}$ synthesized functionally gradient polymeric materials with short conversion times that were several centimeters in thickness. Frontal polymerization may also be used for the consolidation of the stone of historical monuments. ${ }^{15}$ Fiori et al. ${ }^{16}$ cured unsaturated polyester resin using frontal polymerization and used hydroxyethyl acrylate in place of styrene to prepare unsaturated polyester resins. Nason et al. used a mixture of photoinitiators and thermal initiators for the frontal polymerization of acrylate and methacrylates. ${ }^{17,18}$ Hydrogels can be prepared by frontal polymer- ization. ${ }^{19-25}$ Frontal polymerizations can also be carried out in deep-eutectic mixtures. ${ }^{18}$

Although most studies have focused on free-radical chemistry, other reaction mechanisms can be used, including urethane formation, ${ }^{26}$ ring-opening metathesis polymerization, ${ }^{27}$ and frontal epoxy curing. ${ }^{28-31}$

A significant challenge for free-radical frontal polymerization is how to achieve a long pot life and a low front temperature. If we rely on the Arrhenius kinetics of the initiator decomposition, we must trade off pot life for front temperature, that is, a longer pot life means that the front temperature must be allowed to reach a higher value. This affects how much filler may be added and how thin the layer may be and still allow front propagation. Gugg et al. ${ }^{32}$ developed a clever approach to address this issue by using peracrylates, whose decomposition rate increased when copolymerized with the monomer.

Redox systems involving benzoyl peroxide and $\mathrm{N}, \mathrm{N}$-dimethylaniline or persulfate and $N, N, N^{\prime}, N^{\prime}$-tetramethylethylenediamine have been used with frontal polymerization. ${ }^{33-35}$ These systems exhibit fewer bubbles than with the peroxides alone but have short pot lives. To address the pot life issue, McFarland et al. $^{36,37}$ used microencapsulated cumene hydroperoxide (CHP) with and without cobalt naphthenate dissolved in the 


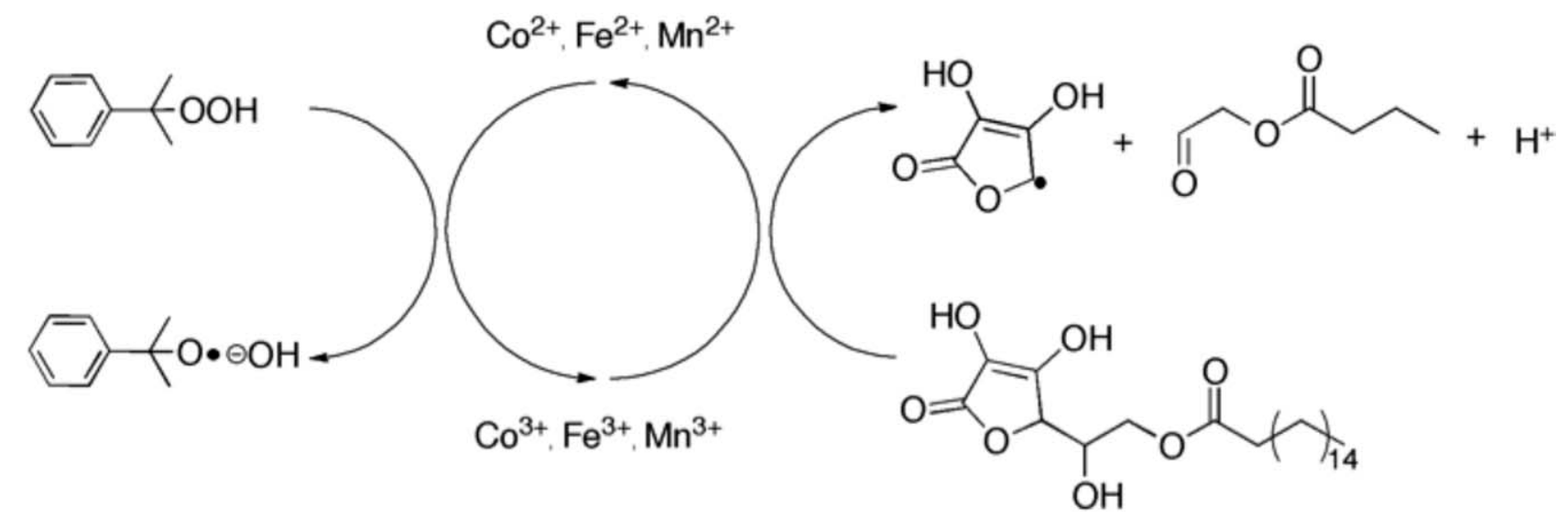

SCHEME 1 Schematic production of free radicals produced by the change in the oxidation state of the metal. A radical is released with each sequential oxidation-reduction cycle. Transition metals like $\mathrm{Co}^{2+}, \mathrm{Fe}^{2}$, and $\mathrm{Mn}^{2+}$ can be oxidized to $\mathrm{Co}^{3+}, \mathrm{Fe}^{3+}$, and $\mathrm{Mn}^{3+}$, respectively. Reductants such as 6-O-palmitoyl-L-ascorbic acid can reduce the metal by the donation of an electron.

monomer. Hydroperoxides are used with cobalt naphthenate in the curing of unsaturated polyester resin. ${ }^{38}$

Scheme 1 shows a redox initiation system with CHP as the oxidant and 6-O-palmitoyl-L-ascorbic acid as the reductant for the oxidized metal. In normal (nonredox) thermal frontal polymerization, the initiator is heated until an oxygen-oxygen bond homolytically cleaves producing two free radicals. This bond can also be cleaved to form two free-radical initiator species by the donation of an electron from a transition metal such as $\mathrm{Cr}^{2+}, \mathrm{V}^{2+}, \mathrm{Ti}^{2+}, \mathrm{Co}^{2+}, \mathrm{Fe}^{2+}$, or $\mathrm{Mn}^{2+39}$

The main goal of this research was to perform radical redox frontal polymerization using the transition metal cobalt to allow propagation with more filler loading and in thinner layers than peroxide systems alone. Achieving this goal might allow adhesives and coatings based on frontal polymerization. ${ }^{40}$ The cobalt used in this research was contained in the polymer, Intelimer 6050X11. The cobalt is encapsulated within an Intelimer polymer, which is synthesized to have crystalline side chains in which cobalt-containing moieties are trapped. The crystalline portions of the Intelimer polymer become amorphous once heated beyond $65{ }^{\circ} \mathrm{C}$. Once the polymer takes on the amorphous form, the cobaltcontaining moiety is exposed and can react with the hydroperoxide. The Intelimer $6050 \times 11$ is $2 \%$ by weight of cobalt. $^{40,41}$

\section{EXPERIMENTAL}

All the chemicals were used as received. Trimethylolpropane triacrylate (TMPTA- $n$ ) technical grade, CHP 80\%, 6-Opalmitoyl-L-ascorbic acid, and benzoin 98\% were obtained from Sigma-Aldrich. Calcium carbonate was obtained from Merck; kaolin clay (Polygloss 90) was obtained from Huber Materials; and Intelimer 6050X11 was obtained from Air Products. The structures of all chemicals are presented in Figure 1.

All frontal polymerization experiments were carried out at ambient temperature and pressure. Initially, the thermal initiator (CHP) was dissolved in the monomer (TMPTA) by mixing the two liquid components in an $80-\mathrm{mL}$ beaker. The solid filler component (Polygloss 90) was then added to the solution. The components were mixed by hand using a stir rod. For the systems containing the Intelimer $6050 X 11$, this component was added next to the mixture. For the redox systems containing both the Intelimer $6050 X 11$ and reducing agent, the Intelimer 6050X11 was added first followed by the addition of the reductant (6-Opalmitoyl-L-ascorbic acid or benzoin). Finally, all of the components were thoroughly mixed. Each viscous mixture was then poured into one of the two molds that had the following dimensions: $15 \mathrm{~cm}$ long $\times 1.7 \mathrm{~cm}$ wide $\times 0.70$ $\mathrm{cm}$ deep or $15 \mathrm{~cm}$ long $\times 1.7 \mathrm{~cm}$ wide $\times 0.35 \mathrm{~cm}$ deep. The mold was prepared by gluing two or four wooden tongue depressors (depending on the desired thickness) on top of one another using wood glue. After molding, a soldering iron was applied to the end of the strip until a polymerization front started.

The front temperature was measured by placing a type " $\mathrm{K}$ " thermocouple wire at multiple points along the strip. An average front temperature was then calculated. This average front temperature was the reported front temperature for each experiment. A movie of each front was recorded and then analyzed to determine the front velocity. The reproducibility was $\pm 10 \%$.

For the systems producing the 0.70 -cm-thick samples, a concentration of 3 phr (parts per hundred resin) CHP was dissolved in $20 \mathrm{~g}$ of monomer (TMPTA) followed by the addition of various amounts of kaolin clay (Polygloss 90). The components were vigorously mixed with a glass stir rod to form a putty-like consistency. The amount of Polygloss 90 added was varied from 35 to 80 phr. All of the molar ratios for the Intelimer were calculated with respect to CHP, whereas the molar ratios for the reductant species were calculated with respect to the cobalt metal. Depending on the trial, the following components were added to the reaction mixture: Intelimer 6050X11 (0.5: 1 molar ratio), Intelimer 
<smiles>C=CC(=O)OCC(CC)(COC(=O)C=C)COC(=O)C=C</smiles>

trimethylolpropane triacrylate<smiles>O=C(c1ccccc1)C(O)c1ccccc1</smiles>

benzoin<smiles>CC(C)(O)c1ccccc1</smiles>

cumene hydroperoxide<smiles>O=C(O[Ge]OC(=O)c1ccc2ccccc2c1)OC(=O)c1ccc2ccccc2c1</smiles>

cobalt naphthenate<smiles>CC(C)(C)[Y4]C(=O)OC[C@H](O)[C@H]1OC(=O)C(O)=C1O</smiles>

6-O-palmitoyl-L-ascorbic acid

FIGURE 1 The structures of all reagents.

$6050 \times 11+6$-O-palmitoyl-L-ascorbic acid (0.5: 1 and 1:1 molar ratio), or Intelimer $6050 \mathrm{X} 11+$ benzoin $(0.5: 1$ and $1: 1$ molar ratios).

For the systems producing the 0.35 -cm-thick samples, $5 \mathrm{phr}$ CHP was dissolved in $10 \mathrm{~g}$ of TMPTA followed by the addition of various amounts of Polygloss 90 ranging from 30 to 50 phr. Finally, $2.32 \mathrm{~g}$ of Intelimer 6050X11 was added, and the formulation was vigorously mixed with a glass stir rod before being molded into a strip.

\section{RESULTS AND DISCUSSION}

The concentration of the thermal initiator is an important factor in frontal polymerization. ${ }^{2,42}$ When the initiator concentration is too low, it is not possible to sustain a front due to heat loss. On the contrary, if the concentration of the initiator is very high, the pot life may be short, making the system less useful. To find an optimal concentration of initiator, several experiments were performed with concentrations of

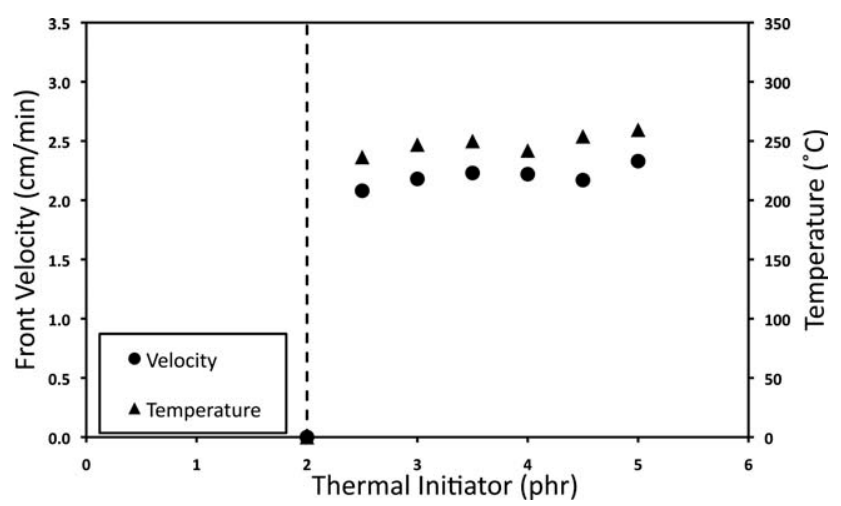

FIGURE 2 Front velocity and temperature as a function of a thermal initiator (cumene hydroperoxide) concentration for a $0.70-\mathrm{cm}$-thick sample with $60 \mathrm{phr}$ kaolin.
CHP ranging from 2 to 5 phr. Figure 2 illustrates the dependence of the front velocity and the front temperature on the concentration of the thermal initiator.

As can be observed in Figure 2, the initiator concentration affected the $T_{\max }$. An increase in the CHP concentration from 2 to 5 phr caused an increase of the $T_{\max }$ from 240 to $260{ }^{\circ} \mathrm{C}$. With CHP concentrations less than $2 \mathrm{phr}$, no front propagated. With concentrations greater than $2 \mathrm{phr}$, the front velocity was weakly dependent on the CHP.

For 0.70 -cm-thick samples and a 3 phr thermal initiator concentration, the front velocity and the front temperature as a function of filler concentration were determined without Intelimer (Fig. 3) and with Intelimer (Fig. 4). The presence of Intelimer caused an average decrease in the front temperature of $\sim 20 \%$. However, more kaolin was required in the Intelimer-containing systems to achieve moldable putty (55 phr) when compared with the Intelimer-free system (20 phr).

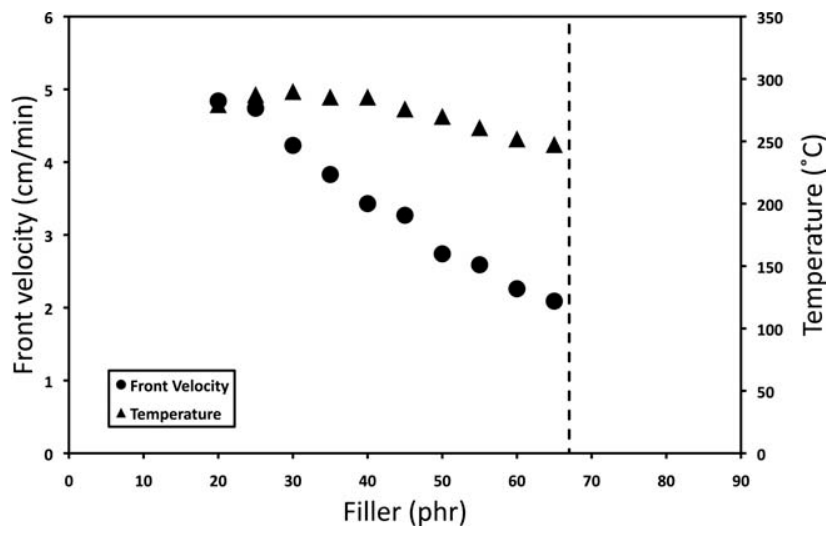

FIGURE 3 Front velocity and temperature as a function of kaolin loading for a $0.70-\mathrm{cm}$-thick sample containing 3 phr cumene hydroperoxide. 


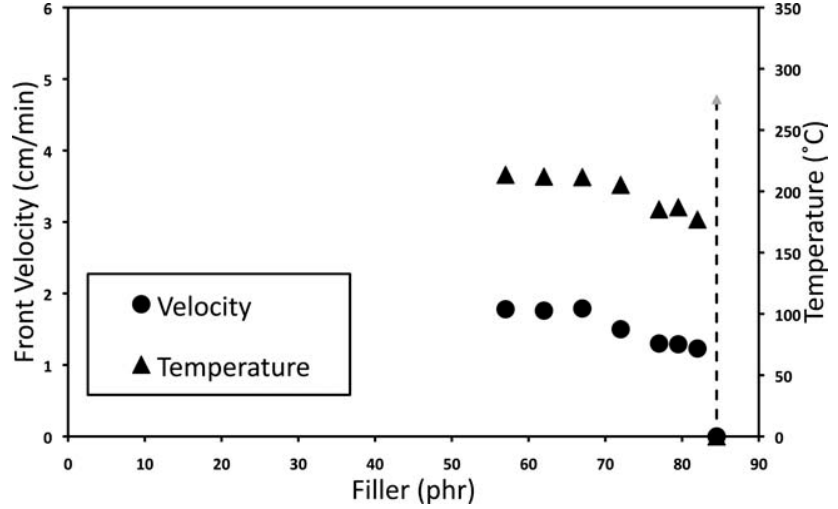

FIGURE 4 Front velocity and temperature as a function of kaolin loading for a $0.70-\mathrm{cm}$-thick sample containing $3 \mathrm{phr}$ cumene hydroperoxide and $3.2 \mathrm{phr}$ Intelimer 6050X11.

The lower temperature and the slower velocity with the Intelimer are a result of the cobalt oxidizing the growing chain and attaching to the end of the chain as a reversible chain terminator for the reaction. ${ }^{43,44}$ This reduces the concentration of radicals, which reduces the rate of polymerization. However, when the Intelimer was used, it was observed that a front could be sustained with higher filler loading than without it. Without Intelimer, the maximum filler loading was 65 phr; however, with the Intelimer, as much as 85 phr filler could be added before the front would quench. This phenomenon was likely caused by the increase in the rate of decomposition of the initiator.

Although the results of the first experiments (lower front velocity) indicated that a thinner layer using cobalt would likely be impossible, the use of cobalt did in fact allow for fronts in thinner layers to be obtained. This can be observed in Figure 5, which illustrates the front velocity and temperature as a function of the filler concentration for systems in a 0.35 -cm layer in the presence of cobalt-containing Intelimer.

It can be observed from Figure 5 that the temperature of the front decreased from 200 to $180{ }^{\circ} \mathrm{C}$ when the filler (Poly-

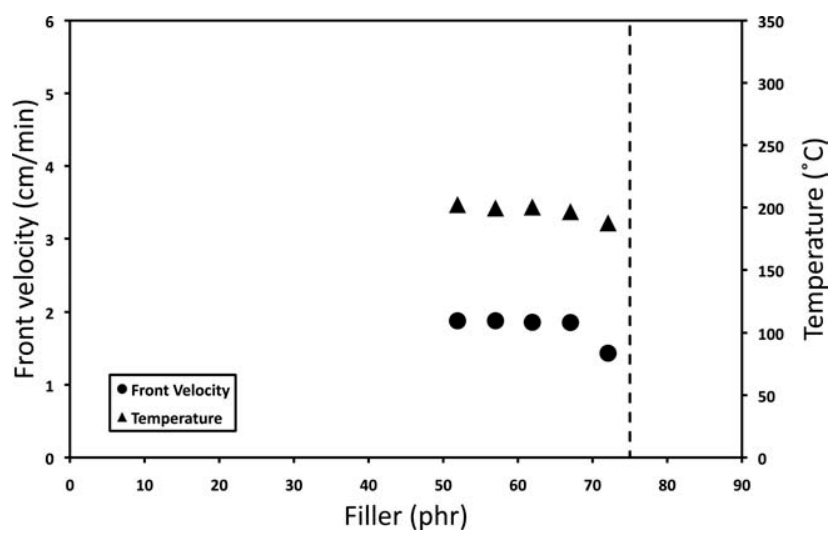

FIGURE 5 Front velocity and temperature as a function of the kaolin loading for a $0.35-\mathrm{cm}$-thick front containing 5 phr cumene hydroperoxide and $3.2 \mathrm{phr}$ Intelimer $6050 \times 11$. The filler used in correlation with these data was kaolin clay (Polygloss 90). gloss $90+$ Intelimer polymer) loading was increased from 52 to 72 phr. It can also be noted that the front velocities decreased from $1.9 \mathrm{~cm} / \mathrm{min}$ to $1.4 \mathrm{~cm} / \mathrm{min}$ when the filler was increased from 52 to $72 \mathrm{phr}$. Therefore, both the front velocity and the front temperature were inversely related to the filler concentration when cobalt was introduced into the system. In the case where no cobalt was added to the system, no front could be sustained at this thickness. The fact that the systems containing the cobalt could sustain a front in these thin layers could be explained by the catalytic effect of the cobalt on the CHP decomposition.

Experiments performed in the absence of Intelimer produced a smooth front with slight curvature, but with Intelimer, the front propagated in a complicated manner (Fig. 6). Such nonplanar modes of propagation have been the subject of much investigation. ${ }^{40,45-51}$ The complexity of the front increases with the value of the effective energy of activation. By reducing the number of propagating radicals, the transition metal reduces the contribution of the energy of activation for the termination step, which increases the effective activation energy. ${ }^{49,50}$

To increase the production of free radicals, two reductants were separately tested: benzoin and 6-O-palmitoyl-L-ascorbic acid. The reductant plays an important role in reestablishing
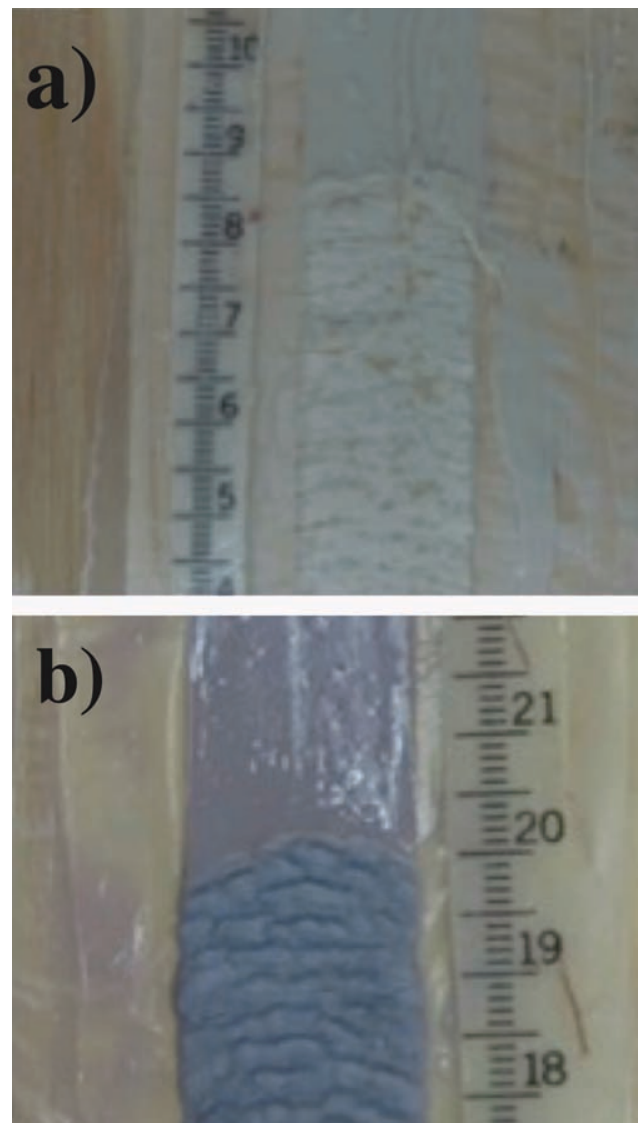

FIGURE 6 Patterns on the surface of the polymer samples: experiment performed in the (a) absence of Intelimer 6050X11 and (b) presence of Intelimer 6050X11. 
the oxidation state. Once the initiator is decomposed, by the oxidation of the metal from $\mathrm{Co}^{2+}$ to $\mathrm{Co}^{3+}$, the metal is reduced by the reductant and the cycle continues until the exhaustion of the hydroperoxide or the reductant. All of the experiments were performed using a 1:1 stoichiometric ratio between the reductant and the transition metal.

The benzoin did not significantly affect the front velocities or front temperatures in the range of 55-82 phr kaolin, which indicates that benzoin was not reacting with the cobalt to generate radicals. Another set of experiments was performed using 6-O-palmitoyl-L-ascorbic acid as the reductant. As can be observed in Figure 7, the system with 6-O-palmitoyl-Lascorbic acid showed an average increase in the front velocity of $\sim 140 \%$ when compared with the experiments without reductant. This result indicates that the oxidation and sequential reduction of the metal cobalt resulted in an increase in the rate of free radical production, causing an increase in the front velocity. The reductant could have also competed with the radicals to react with the cobalt, which reduced the inhibitory effect of the cobalt.

To investigate this large increase in the front velocity when 6-O-palmitoyl-L-ascorbic acid was present, another set of experiments was performed without Intelimer. Similar systems containing TMPTA, CHP, and kaolin clay (differing only in the presence or absence of the reducing agent 6-O-palmitoyl-L-ascorbic acid) were studied. These data are presented in Figure 8.

On comparison of the two sets of experiments illustrated in Figure 8, we can see that there was no change in the average front temperatures or trend of the systems in the range of 40 and 70 phr of filler loading; however, the average front velocity did increase by $\sim 150 \%$ when the reductant (6-Opalmitoyl-L-ascorbic acid) was added in the same range of filler loading. When 6-O-palmitoyl-L-ascorbic acid was added, it was possible to run a front with $>100$ phr of filler, whereas when no 6-O-palmitoyl-L-ascorbic acid was added, the maximum filler loading was found to be only $70 \mathrm{phr}$.

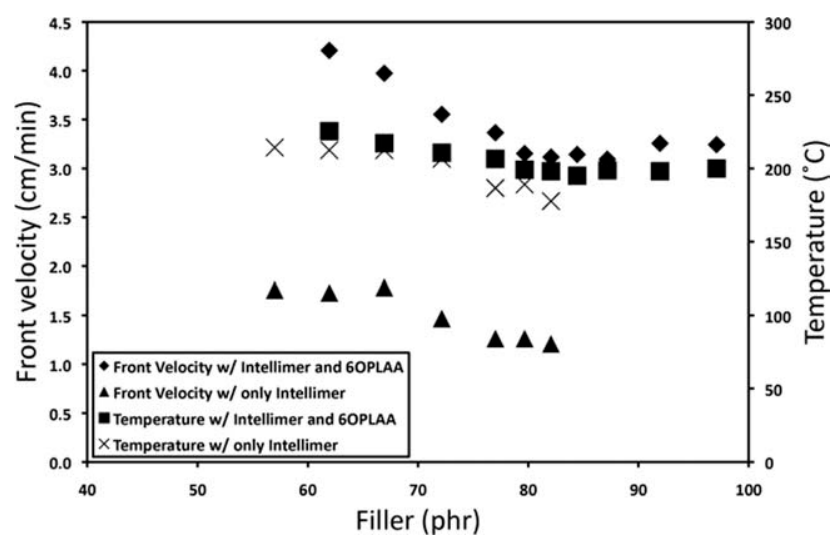

FIGURE 7 A comparison of the front velocities and temperatures as a function of the amount of filler (kaolin) for $0.70-\mathrm{cm}$ thick layers containing $5 \mathrm{phr}$ cumene hydroperoxide and $3.2 \mathrm{phr}$ Intelimer $6050 \times 11$, with and without 6-O-palmitoyl-L-ascorbic acid.

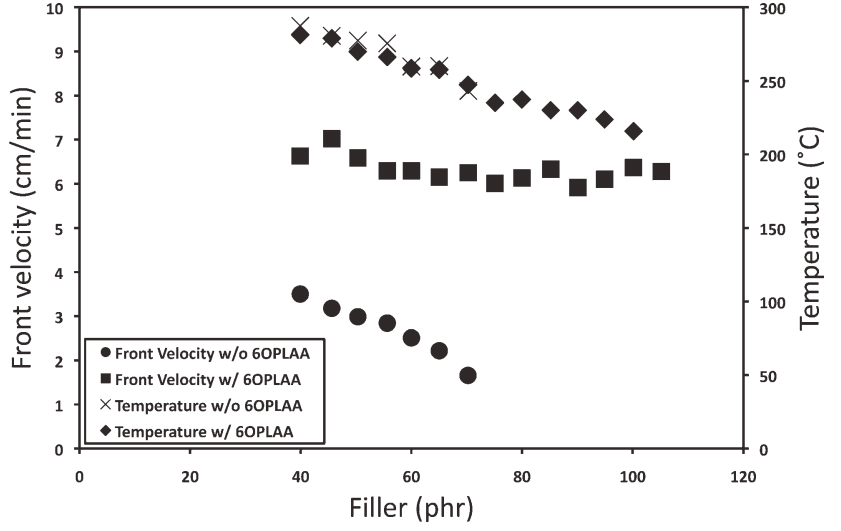

FIGURE 8 A comparison of the front velocities and temperatures as a function of the filler concentration (kaolin) for 0.70 $\mathrm{cm}$-thick fronts containing $5 \mathrm{phr}$ cumene hydroperoxide, with and without 6-O-palmitoyl-L-ascorbic acid.

This result indicated that some other metal could be involved in the redox system because no cobalt was added.

To investigate how the 6-O-palmitoyl-L-ascorbic acid could be involved in the observed phenomena, another set of experiments using a different filler was performed. Figure 9 shows the front velocity and the front temperature as function of the filler loading. The front temperature was not significantly affected by the filler loading. However, the front velocity was significantly higher when kaolin clay was used instead of calcium carbonate, both in the presence of 6-Opalmitoyl-L-ascorbic acid. We attribute the relative increase in the front velocity associated with the use of kaolin clay to transition metal contaminants in kaolin clay, which is consistent with literature reports. ${ }^{52}$

In an attempt to exploit the accelerating effect of kaolin clay while maintaining a usable pot life, a set of experiments using a combination of calcium carbonate and kaolin clay was performed. A pot-life study coupled with frontal

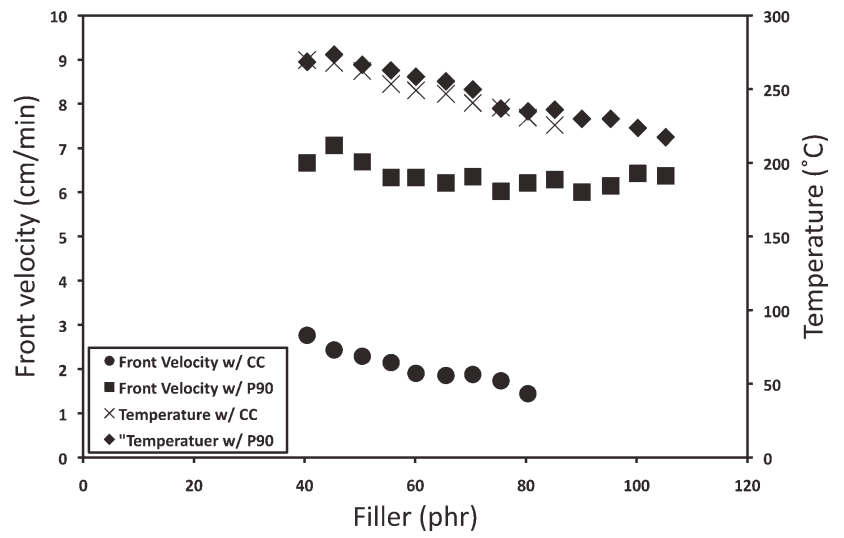

FIGURE 9 A comparison of the front velocities and temperatures as a function of the filler loading for 0.70 -cm-thick layers containing $5 \mathrm{phr}$ cumene hydroperoxide and either calcium carbonate or kaolin (Polygloss 90). 


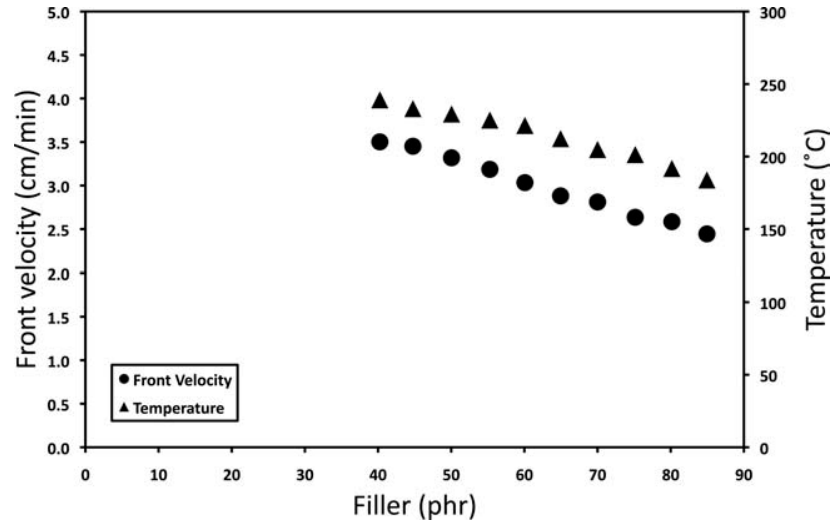

FIGURE 10 Front velocity and temperature as a function of the filler concentration for a $0.35-\mathrm{cm}$-thick layer containing $5 \mathrm{phr}$ cumene hydroperoxide and $3.2 \mathrm{phr}$ 6-O-palmitoyl-L-ascorbic acid. The filler was a mixture of $80 \%$ calcium carbonate and $20 \%$ kaolin clay (Polygloss 90 )

polymerization experiments established that using 80\% calcium carbonate and $20 \%$ kaolin clay as fillers in the presence of 3.2 phr 6-O-palmitoyl-L-ascorbic acid produced a system with a pot life of $90 \mathrm{~min}$ while still being reactive enough to sustain a front of polymerization in a $0.35-\mathrm{cm}-$ thick layer.

Figure 10 shows the data of the front velocity and the front temperature as a function of filler loading (a mixture of $80 \%$ calcium carbonate and $20 \%$ kaolin clay filler). As can be observed in Figure 10, when the loading of the mixture was increased from $40 \mathrm{phr}$ to $80 \mathrm{phr}$, the front temperature decreased from 240 to $180{ }^{\circ} \mathrm{C}$ and the front velocity decreased from 3.5 to $2.5 \mathrm{~cm} / \mathrm{min}$.

\section{CONCLUSIONS}

We studied free-radical frontal polymerization of TMPTA- $n$ with CHP as the initiator and tested the effect of Intelimer $6050 \mathrm{X} 11$, which is a cobalt-containing polymer. The Intelimer melts at $63{ }^{\circ} \mathrm{C}$, at which point the cobalt is available to react with the hydroperoxide via a redox reaction to generate free radicals. As anticipated, the presence of the Intelimer decreased the minimal layer thickness in which a front could propagate and increased the maximum tolerable filler loading for front propagation. The pot life was on the order of days. However, the Intelimer also decreased front velocity and caused nonplanar modes of front propagation.

We also tested the effect of reductants with Intelimer. Benzoin did not significantly affect the velocity or front temperature. However, 6-O-palmitoyl-L-ascorbic acid increased the front velocity by as much as two times while not affecting the front temperature. Interestingly, without the Intelimer, the 6-O-palmitoyl-L-ascorbic acid increased the front velocity (as much as three times) if kaolin was used as filler, but not if calcium carbonate was used. We suppose that this is due to impurities in the kaolin. Using the data obtained from this study, we developed a system containing kaolin and calcium carbonate that could sustain a frontal polymerization in a layer as thin as $0.35 \mathrm{~cm}$ while still maintaining a pot life of $\sim 90 \mathrm{~min}$.

The authors thank Air Products for the Intelimer 6050X11.

\section{REFERENCES AND NOTES}

1 Pojman, J. A.; llyashenko, V. M.; Khan, A. M. J. Chem. Soc. Faraday Trans. 1996, 92, 2825-2837.

2 Chechilo, N. M.; Khvilivitskii, R. J.; Enikolopyan, N. S. Dokl. Akad. Nauk SSSR 1972, 204, 1180-1181.

3 Pojman, J. A.; Elcan, W.; Khan, A. M.; Mathias, L. J. Polym. Sci. Part A: Polym. Chem. 1997, 35, 227-230.

4 White, S. R.; Kim, C. J. Reinforced Plast. Compos. 1993, 12, 520-535.

5 White, S. R.; Kim, C. In International SAMPE Symposium and Exhibition, 37th, Anaheim, CA, March 9-12, 1992, Proceedings (A93-15726 04-23); pp 240-251.

6 Kim, C.; Teng, H.; Tucker, C. L.; White, S. R. J. Comp. Mater. 1995, 29, 1222-1253.

7 Nagy, I. P.; Sike, L.; Pojman, J. A. Adv. Mater. 1995, 7, 1038-1040.

8 Nagy, I. P.; Sike, L.; Pojman, J. A. J. Am. Chem. Soc. 1995, 117, 3611-3612.

9 Pojman, J. A.; Fortenberry, D. I.; Khan, A.; Ilyashenko, V. M. In Synthesis and Characterization of Advanced Materials, ACS Symposium Series No. 681; Serio, M. A.; Gruen, D. M.; Malhotra, R., Eds.; American Chemical Society: Washington, DC, 1998; pp 220-235.

10 Alzari, V.; Nuvoli, D.; Scognamillo, S.; Piccinini, M.; Gioffredi, E.; Malucelli, G.; Marceddu, S.; Sechi, M.; Sanna, V.; Mariani, A. J. Mater. Chem. 2011, 21, 8727-8733.

$11 \mathrm{Hu}$, T.; Chen, S.; Tian, Y.; Pojman, J. A.; Chen, L. J. Polym. Sci. Part A: Polym. Chem. 2006, 44, 3018-3024.

12 Szalay, J.; Nagy, I.; Báyai, I.; DeáK, G.; Bazsa, G.; Zsuga, M. Macromol. Rapid Commun. 1999, 20, 315-318.

13 Chen, S.; Sui, J.; Chen, L.; Pojman, J. A. J. Polym. Sci. Part A: Polym. Chem. 2005, 43, 1670-1680.

14 Pojman, J. A.; McCardle, T. W. (The University of Southern Mississippi). U.S. Patent 6,057,406, 2000.

15 Vicini, S.; Mariani, A.; Princi, E.; Bidali, S.; Pincin, S.; Fiori, S.; Pedemonte, E.; Brunetti, A. Polym. Adv. Technol. 2005, 16, 293-298.

16 Fiori, S. M. G.; Marianai, A.; Ricco, L.; Casazza, E. e-Polymers 2002, 57, 1-10.

17 Nason, C.; Roper, T.; Hoyle, C.; Pojman, J. A. Macromolecules 2005, 38, 5506-5512.

18 Mota-Morales, J. D.; Gutierrez, M. C.; Sanchez, I. C.; LunaBarcenas, G.; del Monte, F. Chem. Commun. 2011, 47, 5328-5330.

19 Washington, R. P.; Steinbock, O. J. Am. Chem. Soc. 2001, 123, 7933-7934.

20 Lu, G. D.; Yan, Q. Z.; Ge, C. C. Polym. Int. 2007, 56, 1016-1020. 21 Yan, Q.; Zhang, W. F.; Lu, G. D.; Su, X. T.; Ge, C. C. Chem. Eur. J. 2006, 12, 3303-3309.

22 Alzari, V.; Mariani, A.; Monticelli, O.; Valentini, L.; Nuvoli, D.; Piccinini, M.; Scognamillo, S.; Bon, S. B.; Illescas, J. J. Polym. Sci. Part A: Polym. Chem. 2010, 48, 5375-5381.

23 Fang, Y.; Yu, H.; Chen, L.; Chen, S. Chem. Mater. 2009, 21, 4711-4718.

24 Caria, G.; Alzari, V.; Monticelli, O.; Nuvoli, D.; Kenny, J. M.; Mariani, A.; Bidali, S.; Fiori, S.; Sangermano, M.; Malucelli, G.; 
Bongiovanni, R.; Priola, A. J. Polym. Sci. Part A: Polym. Chem. 2009, 47, 1422-1428.

25 Alzari, V.; Monticelli, O.; Nuvoli, D.; Kenny, J. M.; Mariani, A. Biomacromolecules 2009, 10, 2672-2677.

26 Mariani, A.; Fiori, S.; Bidali, S.; Alzari, V.; Malucelli, G. J. Polym. Sci. Part A: Polym. Chem. 2008, 46, 3344-3352.

27 Mariani, A.; Fiori, S.; Chekanov, Y.; Pojman, J. A. Macromolecules 2001, 34, 6539-6541.

28 Arutiunian, K. A.; Davtyan, S. P.; Rozenberg, B. A.; Enikolopyan, N. S. Dokl. Akad. Nauk SSSR 1975, 223, 657-660.

29 Chekanov, Y.; Arrington, D.; Brust, G.; Pojman, J. A. J. Appl. Polym. Sci. 1997, 66, 1209-1216.

30 Mariani, A.; Bidali, S.; Fiori, S.; Sangermano, M.; Malucelli, G.; Bongiovanni, R.; Priola, A. J. Polym. Sci. Part A: Polym. Chem. 2004, 42, 2066-2072.

31 Scognamillo, S.; Bounds, C.; Luger, M.; Mariani, A.; Pojman, J. A. J. Polym. Sci. Part A: Polym. Chem. 2010, 48, 2000-2005.

32 Gugg, A.; Gorsche, C.; Moszner, N.; Liska, R. Macromol. Rapid Commun. 2011, 32, 1096-1100.

33 Pojman, J. A.; West, W. W.; Simmons, J. J. Chem. Ed. 1997, 74, 727-730.

34 Yu, H.; Fang, Y.; Chen, L.; Chen, S. Polym. Int. 2009, 58, 851-857.

35 Pujari, N. S.; Inamdar, S. R.; Ponrathnam, S.; Kulkarni, B. D. Macromol. Rapid Commun. 2007, 28, 109-115.

36 McFarland, B.; Popwell, S.; Pojman, J. A. Macromolecules 2004, 37, 6670-6672.

37 McFarland, B.; Popwell, S.; Pojman, J. A. Macromolecules 2006, 39, 53-63.

38 Updegraff, I. H. In Handbook of Composites; Lubin, G., Ed.; Van Nostrand Reinhold: New York, 1982; pp 17-37.

39 Cowie, J. M. G.; Arrighi, V. Polymers: Chemistry and Physics of Modern Materials; CRC Press: Cheltenham, 2008.
40 Pojman, J. A. In Nonlinear Dynamics with Polymers: Fundamentals, Methods and Applications; Pojman, J. A.; Tran-CongMiyata, Q., Eds.; Wiley-VCH Verlag GmbH \& Co. KGaA: Weinheim, 2010; pp 45-68.

41 Bitler, S. P.; Wanthal, M. A.; Kamp, D. A.; Meyers, P. A.; Taft, D. D. J. Adhes. Seal. Council 1997, 243-253.

42 Chechilo, N. M.; Enikolopyan, N. S. Dokl. Phys. Chem. 1975, 221, 392-394.

43 Wayland, B. B.; Poszmik, G.; Mukerjee, S. L.; Fryd, M. J. Am. Chem. Soc. 1994, 116, 7943-7944.

44 Bunck, D. N.; Sorenson, G. P.; Mahanthappa, M. K. J. Polym. Sci. Part A: Polym. Chem. 2011, 49, 242-249.

45 Pojman, J. A.; llyashenko, V. M.; Khan, A. M. Phys. D 1995, 84, 260-268.

46 Pojman, J. A.; Masere, J.; Petretto, E.; Rustici, M.; Huh, D.S.; Kim, M. S.; Volpert, V. Chaos 2002, 12, 56-65.

47 Ilyashenko, V. M.; Pojman, J. A. Chaos 1998, 8, 285-287.

48 Solovyov, S. E.; llyashenko, V. M.; Pojman, J. A. Chaos 1997, 7, 331-340.

49 Masere, J.; Stewart, F.; Meehan, T.; Pojman, J. A. Chaos 1999, 9, 315-322.

50 Pojman, J. A.; Popwell, S.; Fortenberry, D. I.; Volpert, V. A.; Volpert, V. A. In Nonlinear Dynamics in Polymeric Systems, ACS Symposium Series No. 869; Pojman, J. A.; Tran-CongMiyata, Q., Eds.; American Chemical Society: Washington, DC, 2003; pp 106-120.

51 Commissiong, D. M. G.; Gross, L. K.; Volpert, V. A. In Nonlinear Dynamics in Polymeric Systems, ACS Symposium Series No. 869; Pojman, J. A.; Tran-Cong-Miyata, Q., Eds.; American Chemical Society: Washington, DC, 2003; pp 147159.

52 Jepson, W. B.; Rowse, J. B. Clays Clay Miner. 1975, 23, 310-317. 